most of the book's pages. There are some great examples of why one should be wary of simultaneous contrast, and samples as well of color combinations that work. In the feature representation chapter, each subsection has a palette of hues that are of particular use for representing the features being discussed. The back of the book has several pages of color swatches (with accompanying RGB codes) that the author argues are effective when used together on maps. The book's typeface and subheadings are also very well chosen.

The chapter and appendix on layout design are some of the most extensive texts on this topic to be found anywhere. This chapter is broken down into subsections based on the map element being discussed. Best practices, different styling techniques, and placement tips are systematically reviewed for every type of map element one can think of. The chapters on text and color are far more brief, but still prove suitably detailed. The text chapter has several charts illustrating how to determine the ideal text size for your map based on how far away the reader will be - something handy to know when creating poster maps. The chapter on preparing maps for different mediums also adds a variety of useful information on how to embed and produce your maps in different situations.

Some sections of the book, however, are less stellar: the first two chapters, though short, are largely filler. The second chapter, entitled "Creative Inspiration," I found particularly aggravating. It read like a 12 -step program for uninspired GIS professionals. Of course, if you are having trouble finding cartographic inspiration and need a jump start to fuel your design prowess, then this chapter might work for you, as it has sections called "You Can be Creative" and "An Example of How to See." Fortunately, although it is divided into seven sections, the entire chapter spans only six pages and thus, in some ways, better represents the art of concision than of creative induction.

The book suffers from a lack of academic formalism. For example, many citations come from magazines such as ArcUser and Government Technology. Also, I discovered several faux pas in this book that might make trained cartographers cringe. For example, one of the first graphics I found when opening the book was an unprojected map of Minnesota (p. 142). There are a handful of such maps sprinkled throughout the volume. Given that such cartographic errors are common in many GIS textbooks, this by itself is not a reason to avoid the book. It may explain, though, why there is no chapter on map projections.

Due to its emphasis on design alone, at the expense of other fundamental aspects of cartography, I believe this book is most suitable as a secondary text on map design for introductory GIS courses. It is simply not substantial enough to serve as a primary text. I have already recommended GIS Cartography to former GIS students as something to look at before they head out into the world making maps on their own. The book's layout and lush illustrations make it a superb reference book to have handy. Even as an experienced cartographer, the book gave me ideas for future map projects.

This is the book that many practitioners of GIS have been waiting a long time to get their hands on. GIS Cartography is one of the most enjoyable books on cartographic design I have ever read. The author has a great voice throughout the book and a sense of humor that keeps the writing fresh. The book is concise, full of examples, and makes for a perfect quick reference book. Perhaps most usefully to those practicing GIS or learning in a classroom, it was not written by some staid academic who has not designed a map in the past 10 years. Rather, the book has the vibrancy and enthusiasm of someone who is knowledgeable about the demands of modern GIS workplaces, and realistic about the technology available to the average user. This energy is more than enough to help the book overcome its few, forgivable shortcomings.

\section{PRINCIPLES OF MAP DESIGN}

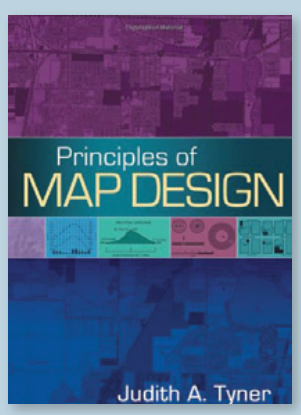

\author{
By Judith A. Tyner.
}

New York City: The Guilford Press, 2010. 259 pages, 197 black and white illustrations, 23 color plates, 3 appendices, bibliography, index. $\$ 60.00$, hardcover.

ISBN: 978-1606235447

\section{Review by: Dan Cole}

In her Preface, the author unpretentiously, yet proudly discusses how she wrote an earlier version of this book in 1992, and observes how map design has remained consistently steadfast in spite of changes in technology. Her new book contains 12 chapters grouped into 5 parts, plus 3 appendices, a bibliography, and an index. At the end of every chapter are suggestions for further reading. These suggestions, combined with the bibliography, provide students and other readers with plenty of resources to pursue additional information.

In the first chapter, "Introduction," Tyner addresses the scope and antecedents of modern cartography. She starts from the recognition that everyone is a mapmaker, whether they are producing pencil sketches with directions, artistic maps in various formats, or professional maps created in GIS. Tyner briefly notes the debate over the relevance of cartography to GIS, a debate due largely to what she sees as frequent misunderstandings as to what a map is. This leads her into the topical question, What Is a Map?, to which 
she answers, a "graphic representation that shows spatial relationships" (pp. 6-7). Tyner then discusses the various kinds of maps (general purpose, special purpose, and thematic), and some of the limitations of maps (generalization and bias). Her discussion of the power of maps, given that maps "are often accepted at face value and their veracity is seldom questioned by users" (p. 11), suggests to the reader that a skeptical eye is important.

The author notes that the mapping process is not linear, involving, as it does, planning, analysis, presentation and production. She rounds out this chapter with a discussion of the antecedents of modern cartography, beginning with the mid-20th century revolution led by Robinson, Jenks and Sherman, who dealt with aspects of technology and communication, and continuing with a discussion of later scholars such as Harley and Pickles, who addressed critical cartography and its social implications.

Chapter 2 is titled "Planning and Composition," and covers the planning and layout of map design. In terms of layout, Tyner notes where to put map elements, including what to include and exclude on a map. She breaks down the goals of design and layout into six related characteristics: clarity, order, balance, contrast, unity and harmony. The author poses a series of thoughtprovoking questions to promote the concept of design as a plan, with the first question being, Is a map the best solution to the problem? Following this section are discussions on cartography's rules and conventions, intellectual and visual hierarchy (including figureground relationships, offering good advice on landwater distinctions), and design constraints (including the shape of the study area, format, scale and text needed). The composition or execution of design of the map covers the basic elements of subject area, title, legend, scale, orientation, inset maps, supplemental text and illustrations, and frames and neatlines. Here, Tyner provides a number of good suggestions on such topics as titles, legends, north arrows, scales, and insets. This chapter finishes with a discussion on the overall appearance (communication and beauty) of the map, plus two apparent afterthoughts on map critique and the use of spec sheets, both of which could have easily been expanded beyond the two sentences allotted.

The third chapter, "Text Material and Typography," addresses the purpose of text on maps: to label, explain, direct or point, and to establish hierarchy or show size. She wisely notes that the word "map" should not be in the title, nor "legend" or "key" in the legend, nor "scale" in the scale. Tyner gives two examples of how not to word a title, and in Figure 3.3, she provides six different sample titles, although the advisability of one of these, "2005," is questionable. From here, the author moves on to label placement, and provides guidelines for labeling water features, cultural linear features, regional names, mountains, and point locations. Tyner also includes important exceptions to standard rules; while "[1]ettering takes precedence over linework" (p. 47), she noted that lettering should not cross shorelines. There is one small misstep here: her example of a halo in Figure 3.8 looks more like a white drop shadow. In terms of the spelling of geographic names, Tyner promotes the authority of the Board on Geographic Names. She also points out the useful "Type Brewer" tool for testing how different type styles work together. Finally, she discusses the importance of editing for typographic errors.

Chapter 4, "Color in Cartographic Design," begins with the statement, "color maps have become ubiquitous" (p. 57). Even so, Tyner advocates caution in its use because color can easily be, and is often, abused. Her text describes the nature and dimensions of color, followed by a discussion on color specification systems such as CIE, Munsell and spot colors. While she mentions that the Pantone Matching System (PMS) is the most common color specification chart, it is unfortunate that no description of PMS is provided. Tyner gives five reasons to use color (three of which come from Robinson 1967'), and she lists a number of good points to be considered when using it. These include problems with hypsometric colors if no legend is provided, the way color perception differs with age, sex, and culture, and whether the map will be printed on paper, shown on a monitor, or projected on a screen. She notes that colors tend to be overused on qualitative maps in GIS, and cautions against use of a color progression for a more than seven-class quantitative map. Simultaneous contrast, and consideration of how a color map will look when reproduced in black and white are also discussed.

Part II, "The Geographic and Cartographic Framework," begins with chapter 5 , "Scale, Compilation, and Generalization." Tyner gives useful discussions on calculating and representing scale, and she intelligently advises against making the scale more precise than the map, as well as to avoid reducing a map designed for a larger scale. Concerning spatial data compilation, she states, "Base data are not the focus of the map. They provide a structural framework for the design and help the map reader to interpret and elaborate the purpose of the map" (p. 78). Data sources may need to be acknowledged either on the map or in an adjoining place in the publication. One must also evaluate those sources in regard to accuracy and reliability. Tyner notes eight operations of map generalization: "selection, simplification, smoothing, grouping, classification, exaggeration, displacement, and symbolization" (p. 83). She provides a table (5.2), plotting her operations against those of six other cartographic publications, but unfortunately left smoothing off her own list. She goes on to describe the governing factors of data generalization: the map's topic and purpose, scale, the reader's abilities, the cartographer's equipment and skills, and the quality of the data.

The sixth and longest chapter, "The Earth's Graticule and Projections," encompasses a wealth of discussion, 
starting with the size and shape of the earth, longitude and latitude, distance, direction, grids, and coordinates. The next section, on map projections, adequately covers their classification, deformation, and projection surfaces including cylindrical, azimuthal, conic, and mathematical projections. Tyner does well to advise the reader that there is no single best projection, but that projections can be used or exploited for their properties. She corrects misperceptions with such statements as "A map that shows constant compass direction is not an azimuthal map" (p. 103). The section on choosing an appropriate projection is quite helpful; it is a topic that is especially needed by a number of GIS users untrained in cartography. She critiques the use of projections in reference to the subject and purpose of the map, the size, shape and location of the subject area, the audience, whether or not to use a graticule, publication and page limitations, projection identification, and the critically important misuse of projections. On this last point, Tyner points out that the geographic projection is often overused. Her example in Figure 6.40 shows the United States in such a format. She fails, however, to note that Alaska is both shrunken, rotated, and not in the same geographic coordinate system, thus adding to the confusion.

Part III, "Symbolization," includes three chapters, starting with the "Basics of Symbolization." The author notes that symbolization serves as an alternative to text or numbers on maps. She categorizes spatial phenomena on maps in terms of form, continuity and geographic location; and she follows this with the classification of geographic data and the visual variables of point, line and area symbols. Again, Tyner compares her list of visual variables against those previously published by other cartographers, although a color plate would have been helpful. She goes on to give general guidelines and examples of what to do and not to do when portraying geographic phenomena.

Chapter 8, "Symbolizing Geographic Data," logically follows with discussions of qualitative and quantitative point, line, area, and volume symbols. Unfortunately, Guilford Press inserted all the color plates in the middle of this chapter, instead of in a less intrusive location between chapters. This placement disrupts the discussion of dot maps and, especially, the comparison between Figures 8.2 and 8.3. Segregation aside, I am not convinced that the hand-drawn series of dot maps in Figure 8.2 provides a better example than does Figure 8.3B. Nonetheless, Tyner provides excellent reasoning throughout the rest of this chapter on proportional versus range-graded point symbols, including design considerations in maps (placement, filling and overlapping of circles) and in legends. Brief discussions are given to symbolizing qualitative and quantitative linework and areal data, while a more extensive portion of the text is devoted to symbolizing volume data. Also helpful for the neophyte are her comments on dasymetric and unclassed choropleth maps, as well as her warning that designing a choropleth map requires examining the data before choosing a classification scheme. She finishes this chapter with line/volume symbolization involving isarithms, and defines the difference between isometric and isoplethic lines.

The ninth chapter, "Multivariate Mapping," presents techniques for combining two or more variables in a single map using point and areal symbolization, pie charts, Chernoff faces, and graphs. Tyner wisely points out the many design considerations, limitations, and problems for each. The increased use of color through improved computer and printing technology has further enabled the expanded use of multivariate maps, and, fortunately, she notes the research of Olson, Eyton, and Brewer, who sequentially built upon each other's work in providing guidelines for optimal display.

Part IV, "Nontraditional Mapping," starts with chapter 10, "Cartograms and Diagrams." The author covers the various types of cartograms: 1 ) value-by-area, contiguous (rectangular and topologically correct) and non-contiguous, 2) variations, Dorling and Demers, 3) bivariate, and 4) distance-by-time. In doing so, she also identifies the advantages and disadvantages of each. She adds a short discussion of diagrams and schematic maps, noting the lack of guidelines but still emphasizing the goals of "clarity, simplicity and speed of interpretation" (p. 199).

Chapter 11, "Continuity and Change in the Computer Era," starts with a discussion of digital and online maps (MapPoint, Google Maps, Google Earth, MapQuest, and Navteq). Tyner goes on to examine animated maps, which have become especially popular since the advent of PCs. Within this section, she reviews Harrower's important challenges for designing animated maps, which include: disappearance (how long map features and text stay viewable), attention (directing the reader), complexity (or simplicity of the message), and confidence (how well the map reader understands the message). Concerning design recommendations for animated maps, she advises the use of larger text, thicker line weights, brighter colors, and more generalized base maps. The chapter is completed with a series of short sections on sound maps, haptic (electronic tactile) maps, multimedia maps, and web maps. For design considerations, she promotes the use of ColorBrewer and TypeBrewer for optimal displays.

Part V, "Critique of Maps," is also the final chapter, "Putting It All Together." At this point, regarding map editing and evaluation, Tyner wisely points out "that there is no perfect map" (p. 214), and reminds her readers to review the questions posed in chapter 2 . She then describes six potential makeovers, with before and after maps providing readers with various design concepts to resolve possible problems. She finishes the text with the hope "that the reader takes away from this book an 
appreciation of the importance of design as a decisionmaking process." (p. 222).

The book is rounded off with three appendices (commonly used projections, web resources, and glossary), a bibliography, and an index. Overall, in spite of the quibbles noted, I believe that she has successfully written a map design text to be used widely by students and professionals alike.

\section{Notes}

1. Robinson, Arthur. 1967. "Psychological Aspects of Color in Cartography." International Yearbook of Cartography 7: 50-61. 